\section{Стратегия пространственного развития: новый этап или повторение старых ошибок?}

Н.Н. МИХЕЕВА, доктор экономических наук,

Институт народнохозяйственного прогнозирования РАН, Москва. E-mail: mikheeva_nn@mail.ru

В статье обсуждаются вопросы разработки на федеральном уровне документов стратегического планирования, касающихся пространственного развития. Показано, что стратегии долгосрочного развития федеральных округов, принятые федеральным правительством в 2010-2011 гг., не стали реальным инструментом решения проблем пространственного развития. На основе анализа официальных документов, регламентирующих разработку стратегии пространственного разви тия, обсуждаются теоретические предпосылки стратегии и проблемы, которые следуют из их использования. Показано, что при сохранении в долгосрочной перспективе низких темпов развития российской экономики возможности целенаправленного воздействия на пропорции пространственного развития ограничены, существуют значительные риски сохранения сложившихся трендов. Ключевые слова: стратегия пространственного развития, региональные факторы роста, специализация, экономический рост

Региональное стратегическое планирование является в настоящее время, вероятно, самым активно развивающимся направлением прикладных региональных разработок. Пик подготовки региональных стратегий пришелся на 2008-2010 гг., когда после принятия Концепции социально-экономического развития Российской Федерации ${ }^{1}$ (КДР-2020) были разработаны или актуализированы стратегии развития федеральных округов, абсолютного большинства субъектов Федерации, множества городов и муниципалитетов. Новая волна разработки региональных стратегий возникла после принятия в 2014 г. федерального закона «О стратегическом планировании в Российской Федерации» (Ф3 № 172), в рамках реализации которого формируется система документов стратегического планирования.

Качественно новым этапом регионального стратегирования стало появление в составе документов стратегического

Концепция долгосрочного социально-экономического развития Российской Федерации на период до 2020 года [Эл. ресурc]. URL: http://www.consultant.ru/document/cons_doc_LAW_82134/28c7f9e359e8af09d7244d8033c66928fa27e527/ (дата обращения: 14.02.2018). планирования федерального уровня стратегии пространственного развития (СПР) - документа, который в соответствии с законом о стратегическом планировании должен определить приоритеты, цели и задачи регионального развития Российской Федерации, меры по их достижению и решению.

После принятия Ф3 № 172 прошло три с половиной года, система документов стратегического планирования, в том числе стратегия пространственного развития, все еще находится в стадии разработки. Однако в настоящее время принят ряд нормативных документов, регламентирующих ее разработку, Министерством экономического развития представлены концептуальные положения стратегии, утверждена концепция СПР, анализ которых позволяет показать общие черты данной стратегии и выявить проблемы, которые могут возникнуть при ее разработке и реализации.

\section{Как сработали принятые стратегии федерального уровня}

Анализ стратегий социально-экономического развития субъектов Федерации широко представлен в публикациях, в которых рассмотрены методология разработки, сильные и слабые стороны стратегий [Жихаревич, Прибышин, 2014; Журба и др., 2016; Ильина и др., 2016; Селиверстов, 2013]. Рейтинговым агентством «Эксперт» составлен рейтинг региональных стратегий по их состоянию на 2013 год [Рейтинг., 2013]. Большинство авторов сходятся во мнении, что региональные стратегии не согласованы друг с другом, не обеспечивают сбалансированности развития, в них слабо проработаны приоритеты и механизмы реализации стратегических целей. Тем не менее они рассматриваются как действенный инструмент конкуренции регионов за ресурсы, прежде всего инвестиции.

В отличие от разработанных на региональном уровне стратегий социально-экономического развития субъектов Федерации, стратегии долгосрочного развития федеральных округов (макрорегионов) должны создаваться на федеральном уровне, формально они и разрабатываются (по крайней мере, принимаются) федеральными органами государственной власти.

До настоящего времени официально принятыми документами федерального уровня, определяющими перспективы развития 
отдельных территорий, были только стратегии федеральных округов, Дальнего Востока и Байкальского региона. Все они разрабатывались либо актуализировались после принятия КДР-2020 и были призваны спроецировать на территорию целевые установки КДР-2020. Все стратегии были представлены Министерством регионального развития и утверждены Правительством РФ.

Нормативных документов, регламентировавших разработку стратегий для федеральных округов, на тот момент не было, и методология и формат стратегий были отданы на откуп разработчикам, действовавшим автономно. Цели и приоритеты долгосрочного развития федеральных округов в различных вариациях повторяют целевые установки КДР-2020, предполагавшей переход к инновационному варианту развития страны. Кроме того, целевым ориентиром КДР-2020 было заявлено обеспечение сбалансированного социально-экономического развития субъектов Российской Федерации, сокращение уровня межрегиональной дифференциации в социально-экономическом состоянии регионов и качестве жизни. Таким образом, стратегии федеральных округов предполагали к 2020 г. кардинальное изменение трендов и пропорций пространственного развития.

Анализ реальной динамики показывает, что проблемы пространственного развития, отмечавшиеся в том числе и в стратегиях, продолжают усугубляться. Пространственное развитие остается инерционным, признаков изменения его траекторий пока не обнаруживается. Подтверждением этому служит сравнение реальной динамики с целевыми и прогнозными показателями стратегий, представленными в различных форматах с разным набором индикаторов, что не позволяет сформировать на их основе показатели для страны в целом. Однако, как и в случае стратегий субъектов Федерации [Мельникова, 2013], стратегии федеральных округов характеризуются чрезмерным оптимизмом, хотя и проявляется он для разных округов в разной степени.

В Стратегии социально-экономического развития Центрального федерального округа на период до 2020 г. $^{2}$ среднегодовой темп роста за 2002-2008 гг. экстраполирован на период до 2020 г., что поставило под сомнение корректность такого

${ }^{2}$ Стратегия социально-экономического развития Центрального федерального округа на период до 2020 года. [Эл. pecypc]. URL: http://docs.cntd.ru/document/902302272 (дата обращения: 02.02.2018). расчета уже в 2009 г. Реальные темпы роста производства в округе в 2010-2015 гг. были более чем в три раза ниже прогнозных, что не позволит к 2020 г. достичь предполагаемых в стратегии целевых показателей по ВРП. В стратегии не были представлены оценки ресурсов, в частности инвестиций в основной капитал, которые требовались для достижения предполагаемых объемов производства и развития социальной сферы.

Стратегия социально-экономического развития Северо-Западного федерального округа на период до 2020 г. $^{3}$ содержит подробный перечень целевых показателей социально-экономического развития макрорегиона, который сформирован на основе базового варианта прогноза, а также сравнение показателей по вариантам прогноза (пессимистического, оптимистического и базового). Реально достигнутые к 2015 г. показатели оказались даже ниже пессимистического варианта прогноза.

В Стратегии социально-экономического развития Южного федерального округа на период до 2020 г. ${ }^{4}$ представлен прогноз основных показателей развития округа и субъектов Федерации в соответствии с двумя сценариями - консервативным и инновационным. В отличие от предыдущих чрезмерно оптимистичных прогнозов в случае ЮФО гипотезы относительно динамики развития округа оказались более реалистичными. Фактические значения показателей в среднесрочном периоде -2010-2013 гг. либо находились в интервале между значениями консервативного и инновационного вариантов (темпы роста ВРП), либо превышали даже инновационный вариант. Однако с учетом падения в 2014-2016 гг. целевые показатели по динамике ВРП, инвестиций и реальных доходов населения существенно отстают от предполагавшихся в стратегии, что сводит к минимуму вероятность достижений целевых показателей стратегии к 2020 г.

В отличие от предыдущих документов Стратегия социально-экономического развития Северо-Кавказского федерального

\footnotetext{
${ }^{3}$ Стратегия социально-экономического развития Северо-Западного федерального округа на период до 2020 года [Эл. pecypc]. URL: http://docs.cntd.ru/document/902317621. (дата обращения: 02.02.2018).

${ }^{4}$ Стратегия социально-экономического развития Южного федерального округа на период до 2020 года [Эл. ресурc]. URL: http://docs.cntd.ru/document/902301126. (дата обращения: 02.02.2018).
} 
округа ${ }^{5}$ принята на период до 2025 г. Однако, как и в предыдущих случаях, фактические темпы роста ВРП и промышленности в 2008-2016 гг. существенно отставали от прогнозных, завышенным почти в 1,5 раза оказался даже инерционный вариант прогноза. Оценки инвестиционных ресурсов, необходимых для реализации стратегии, в документе не были представлены.

В Стратегии социально-экономического развития Приволжского федерального округа до 2020 г. ${ }^{6}$ целевые прогнозные индикаторы представлены по отношению к низкому уровню 2009 г., относительно невысокие показатели восстановления экономики в 2010-2011 гг., предполагавшиеся в прогнозе, были превышены практически по всем параметрам, кроме реальных доходов населения. Принятые в прогнозе гипотезы относительно интенсивного роста экономики после 2014 г. на уровне 7-8\% в год оказались чрезмерно оптимистичными, наиболее далекими от реальности были прогнозы инвестиций и доходов населения.

Стратегия социально-экономического развития Уральского федерального округа на период до 2020 г. $^{7}$ включает сценарный прогноз для макрорегиона и входящих в его состав субъектов Федерации. Целевые показатели сформированы на базе инновационного варианта прогноза, однако ближе всего к фактическим показателям оказался инерционный вариант, хотя и в этом случае фактические темпы ниже прогнозных по всем индикаторам, кроме инвестиций в основной капитал.

В Стратегии социально-экономического развития Сибири до 2020 г. ${ }^{8}$ приведены три блока целевых показателей: динамика основных индикаторов по базовому сценарию; целевые индикаторы развития инновационной системы Сибири и внешнеэкономической деятельности. Формат данных не позволяет провести сопоставление целевых (прогнозных) показателей с фактическими,

${ }^{5}$ Стратегия социально-экономического развития Северо-Кавказского федерального округа до 2025 года [Эл. pecypc]. URL: http://www/consultant.ru/LAW170425_0_20171 016_144356_55113.rtf. (дата обращения: 02.02.2018).

${ }^{6}$ Стратегия социально-экономического развития Приволжского федерального округа до 2020 года [Эл. pecypc]. URL: http://lawru.info/dok/2011/02/07/n34655.htm. (дата обращения: 02.02.2018)

${ }^{7}$ Стратегия социально-экономического развития Уральского федерального округа на период до 2020 года [Эл. pecypc]. URL: http://docs.cntd.ru/document/902307636. (дата обращения: 02.02.2018).

${ }^{8}$ Стратегия социально-экономического развития Сибири до 2020 года [Эл. ресурс]. URL: http://docs.cntd.ru/document/902229380 (дата обращения: 02.02.2018). поскольку приведенные в документе показатели за 2008 г. (отчетный) существенно отличаются от данных Росстата.

В Стратегии социально-экономического развития Дальнего Востока и Байкальского региона на период до 2025 г. ${ }^{9}$ базовый сценарий развития макрорегиона увязан с инновационным сценарием КДР-2020. Представленные в документе данные также не позволяют сформировать набор показателей, оценивающих степень достижения целевых показателей стратегии (вероятные ошибки в таблицах, существенные отличия отчетных данных от статистики Росстата), однако, как и в предыдущих случаях, в прогнозе предполагаются очень высокие темпы роста экономики макрорегиона.

Причины нереальности прогнозов и целевых показателей стратегий очевидны: экономический кризис 2009 г., кардинальное изменение внешних условий развития после 2014 г. и последовавший за этим экономический кризис, в результате которых не сложились предполагавшиеся в стратегиях условия для развития страны в целом. Однако региональная политика также оставалась инерционной, не были задействованы механизмы, нацеленные на реализацию стратегий. Кроме того, сами стратегии имели ряд существенных недостатков, явившихся результатом принятой схемы их разработки, прежде всего их несогласованности друг с другом.

Принципиальным моментом, характеризующим стратегии федеральных округов, является их автономность. Поскольку цели и приоритеты КДР-2020 были перенесены на уровень регионов, то формально все стратегии согласованы с общенациональной стратегией, чего нельзя сказать о количественных параметрах, особенно об оценке ресурсов, необходимых для реализации стратегий (в ряде случаев они вообще не оценивались).

Прогнозы, на основании которых разрабатывались стратегии, в большинстве случаев были построены путем пролонгации высоких темпов роста 2000-2008 гг, поэтому даже консервативные (инерционные) варианты оказались далеки от реалий, сложившихся после 2008 г. Чрезмерный оптимизм «базовых» и «оптимистичных» прогнозов был также задан исходными условиями прогноза. Стратегии федеральных округов разрабатывались в развитие КДР-2020, в качестве целевого варианта

\footnotetext{
${ }^{9}$ Стратегия социально-экономического развития Дальнего Востока и Байкальского региона на период до 2025 года [Эл. ресурc]. URL: http://docs.cntd.ru/document/902195483. (дата обращения: 02.02.2018).
} 
в которой был принят инновационный вариант развития РФ $\Phi^{10}$. Предполагавшиеся в Концепции на долгосрочный период условия развития страны оказались нереальными уже в 2009-2010 гг., в дальнейшем разрыв между прогнозными и реально достигнутыми показателями только увеличивался.

Логика построения документов стратегического планирования предполагает их периодическую актуализацию и корректировку целевых показателей с учетом фактических данных. В отношении КДР-2020, а также стратегий социально-экономического развития федеральных округов такая корректировка не проводилась. В этой связи целевые показатели стратегий развития федеральных округов на период до 2020 г. в настоящее время представляют собой набор бесполезных цифр.

\section{Замысел стратегии пространственного развития в законе о стратегическом планировании}

Принятие в 2014 г. закона «О стратегическом планировании в Российской Федерации», предусматривавшего в качестве составной части разработку Стратегии пространственного развития, породило надежды на то, что проблемы российских регионов и российского пространства в целом окажутся в центре внимания федеральных властей, или, по крайней мере, регионы получат обоснованный ответ на вопросы о том, какие перспективы их ожидают.

Стратегия пространственного развития (СПР) является принципиально новым для России документом, сочетающим в себе подходы стратегического и территориального планирования. Вопросы о том, что должна представлять собой СПР, неоднократно возникали еще на стадии обсуждения проекта закона о стратегическом планировании, причем оспаривались не только возможное содержание и функции стратегии, но и целесообразность её включения в закон, т.е. принятия федеральной властью на себя обязательства такой документ разрабатывать и реализовывать.

В идейном плане СПР является некоторым аналогом генеральной схемы развития и размещения производительных сил и генеральной схемы расселения, которые в условиях плановой

\footnotetext{
${ }^{10}$ Приложение № 1 к Концепции долгосрочного социально-экономического развития Российской Федерации на период до 2020 г.
}

экономики определяли перспективы пространственного развития и были важным инструментом регулирования пространственного развития. Долгосрочные перспективы развития и размещения народного хозяйства определялись в рамках трех основных документов: Комплексной программы научно-технического прогресса на 20 лет, Концепции экономического и социального развития СССР и Генеральной схемы (прогноза) развития и размещения производительных сил СССР на 15 лет [Адамеску, 2016; Смирнова, 2010]. При этом Генеральная схема была центральной подсистемой в составе нескольких десятков отраслевых и пятнадцати территориальных схем развития и размещения производительных сил. Именно «плановые корни» схем развития и размещения были основным аргументом противников включения стратегии пространственного развития в состав системы документов стратегического планирования.

Принятые нормативные документы определяют лишь общие черты СПР, вопрос о том, на каких научно-методологических основах она будет построена и каким будет ее формат, остается открытым. Из закона о стратегическом планировании следует, что «Стратегия пространственного развития Российской Федерации разрабатывается в соответствии с основами государственной политики регионального развития Российской Федерации в целях реализации основных положений стратегии социально-экономического развития Российской Федерации и стратегии национальной безопасности Российской Федерации, определяет приоритеты, цели и задачи регионального развития Российской Федерации и меры по их достижению и решению»» ${ }^{11}$, в ее состав включаются предложения о совершенствовании системы расселения и приоритетных направлениях размещения производительных сил.

Порядок разработки СПР был утвержден Правительством РФ $\Phi^{12}$. Предполагаемая структура этого документа включает ряд стандартных блоков: анализ особенностей и проблем

${ }^{11}$ Федеральный закон от 28 июня 2014 г. № $172-Ф 3$ «О стратегическом планировании в Российской Федерации» (с изм. и доп.). Ст. 20 [Эл. ресурс]. URL: http://Consultant. ru>document/cons_doc_LAW_164841/ (дата обращения: 02.02.2018).

${ }_{12}$ Постановление Правительства РФ от 20.08.2015 № 870 «О содержании, составе порядке разработки и утверждения стратегии пространственного развития Российской Федерации, а также о порядке осуществления мониторинга и контроля ее реализации» [Эл. pecypc]. URL: http://www.consultant.ru/document/cons_doc_LAW_185091/ (дата обращения: 02.02.2018) 
пространственного развития; принципы и приоритеты, цели и задачи; сценарные варианты пространственного развития, в том числе приоритетный; этапы реализации стратегии и целевые показатели для каждого этапа; механизмы достижения установленных приоритетов.

Специфика СПР отражена в блоке, названном «основные положения в сфере пространственного развития», который включает приоритеты совершенствования системы расселения; направления изменения региональной структуры экономики; перспективные конкурентные преимущества и экономическую специализацию субъектов Федерации; прогноз их потребности в трудовых ресурсах и развитии федеральной инфраструктуры; перечень потенциальных территорий опережающего роста и размещение национальных технологических платформ; направления интеграции России в евразийское и мировое экономическое пространство; состав макрорегионов на территории России и типологию российских регионов и городов.

Очевидно, что указанные «основные положения» строятся на некотором теоретическом фундаменте, в соответствии с которым в основе стратегии пространственного развития должны лежать определение перспективной экономической специализации субъектов Федерации, а также типология регионов и городов. Эти положения вызывали вопросы еще на стадии подготовки документа. Как показала практика разработки проекта концепции СПР, они оказались весьма уязвимыми с теоретической и практической позиций.

В законе определено, что СПР должна учитываться при разработке и корректировке документов стратегического планирования в целях реализации полномочий органов государственной власти Российской Федерации по предметам ведения Российской Федерации, а также совместного ведения Российской Федерации и ее субъектов. Однако круг перспективных направлений пространственного развития, которые предполагается рассмотреть в СПР, достаточно широк. Он отражает как направления, которые может (либо намерено) регулировать федеральное Правительство, так и те, которые к предметам регулирования не относятся.

\section{Концепция стратегии \\ пространственного развития}

В отличие от генеральных схем развития и размещения производительных сил, которые основывались на идеях планового формирования территориальных пропорций, общепринятой концепции перспективной организации российского пространства нет ни в теории, ни на практике. Мнения относительно того, как решать пространственные проблемы России в будущем, находятся в диапазоне от «все проблемы решит рынок» до «решить проблемы может только государство».

Научные основы концепции СПР были подготовлены подведомственной организацией Минэкономразвития - Советом по изучению производительных сил. Кроме того, министерством была создана экспертная рабочая группа, которая включала представителей разных научных направлений и организаций. В результате многочисленных обсуждений был сформирован рабочий вариант концепции, который представлял собой некоторый консенсус позиций разработчиков и экспертов. Основные идеи и методические подходы к разработке концепции СПР были представлены на XV Общероссийском форуме «Стратегическое планирование в городах и регионах» в октябре 2016 г. в СанктПетербурге.

СПР предлагалось строить на основе определенных принципов [Концепция.., 2016; Чугуевская, 2016, 2017], в числе которых: пространственное сплочение - обеспечение территориальной целостности России и её связности; пространственная доступность социальных благ - обеспечение равных возможностей для реализации прав и свобод граждан за счет сокращения чрезмерных межрегиональных и внутрирегиональных различий в уровнях социально-экономического развития субъектов Российской Федерации и муниципальных образований; комплексный подход учёт геополитических факторов в неразрывной связи с экономическими и социальными, гармонизация макроэкономической, отраслевой и социальной эффективности реализации проектов пространственного развития, обеспечение их экологической ориентированности; сбалансированность пространственного развития - предотвращение процессов сверхконцентрации и дальнейшего оттока населения Сибири и Дальнего Востока, депопуляции сельских территорий и малых городов, содействие 
появлению новых территорий роста, инфраструктурное обеспечение пространственного развития экономики и социальной сферы; взаимная дополняемость системы государственного регулирования и рыночных механизмов саморегулирования пространственного развития.

Еще один принцип, определяющий, на наш взгляд, всю идеологию разработки СПР, - безусловная ценность каждого места: дифференцированный подход к определению перспектив пространственного развития, позволяющий выявить свои источники экономического роста для различных территорий. Именно этот принцип отражает теоретическую базу, на которой предполагалось строить стратегию - теорию эндогенного пространственного роста, а также современные подходы, которые закладываются в долгосрочные стратегии пространственного развития Евросоюза [Making.., 2014; Capello.., 2014], - уникальность и ценность каждой территории, которая определяется не только природно-ресурсным и экономическим потенциалом, но и качеством человеческого капитала, историко-культурными и национальными особенностями.

Проект концепции оказался эклектичным, поскольку был сформирован в результате многочисленных обсуждений и попыток учесть различные точки зрения, тем не менее он содержал ряд интересных и аргументированных предложений. Но в официально утвержденной в мае 2017 г. Концепции $\mathrm{CПР}^{13}$ идеи, предлагавшиеся в проекте концепции, были изменены настолько, что порою утрачивали первоначальный смысл. Однако именно этот документ и должен быть положен в основу Стратегии.

Мы не ставили своей задачей подробный анализ содержания документа, отметим лишь некоторые положения, теоретическая обоснованность которых вызывает вопросы.

\section{«Проблемные» положения Концепции СПР}

В качестве основных задач Стратегии названо определение, с учетом конкурентных преимуществ субъектов Федерации, их приоритетных экономических специализаций и на этой основе -

${ }^{13}$ Концепция Стратегии пространственного развития Российской Федерации на период до 2025 г. Утв. зам. Председателя Правительства Российской Федерации Д.Н. Козаком 22 мая 2017 г. [Эл. pecypc]. URL: http://src-sakha.ru/wp-content/uploads/2017/06/170522 Kontseptsiya-SPR-RF Kozak2.pdf (дата обращения: 02.02.2018). оценка перспективных направлений размещения производительных сил и развития инфраструктуры. Таким образом, определение перспективных специализаций субъектов Российской Федерации является центральным пунктом разработки Стратегии.

Такой подход поднимает два типа вопросов: во-первых, как определить перспективную специализацию региона, во-вторых, как использовать данные о перспективной специализации, если ее удастся корректно оценить?

Проблемы выделения приоритетных отраслей и видов деятельности, которые будут формировать экономику будущего, являются общими для всех документов стратегического планирования, в принципе приоритеты развития существующих отраслей и формирования новых должны быть определены стратегией социально-экономического развития Российской Федерации на основе прогноза научно-технологического развития. Однако в СПР поставлены специфические задачи - выявление отраслевых приоритетов (перспективных специализаций) для субъектов Федерации. Специализация региона характеризует его место в системе территориального разделения труда. Перспективная специализация региона может быть определена только в зависимости от того, какое место займет регион в будущем в рамках общенационального рынка, а российская экономика - в системе международных рынков. То и другое существенно зависит от того, какой сценарий развития страны в целом и конкретного региона будет реализован в перспективе.

Обоснованным представляется определение перспективной специализации регионов в рамках долгосрочного прогноза развития России в разрезе субъектов Федерации, учитывающего их межрегиональные взаимодействия и возможности интеграции в международные рынки. Однако в Концепции в числе факторов, определяющих приоритетные экономические специализации регионов, названы: природоресурсная обеспеченность территорий, их геоэкономическое положение, уникальные природные ландшафты, культурное наследие, наличие крупных агломераций, климатические условия, сложившаяся структура производства, научный потенциал и наличие высококвалифицированных кадров. Потенциальные позиции региональных предприятий на национальном и международном рынках в число таких факторов не включены, 
т.е. перспективные специализации предполагается определять для каждого региона изолированно.

Действительно, сочетание указанных факторов создает условия для развития тех или иных отраслевых комплексов, которые могут обеспечить формирование перспективной специализации региона, однако реализоваться эти условия могут только при наличии рыночного спроса на продукцию и услуги, предлагаемые отраслями специализации. Для российских регионов, большая часть которых имеет невысокий экономический потенциал, эта проблема стала критической из-за падения как инвестиционного, так и потребительского спроса. Узость региональных рынков, их слабая межрегиональная связанность, барьеры для выхода региональных предприятий на общенациональный и международные рынки вызвали сокращение или стагнацию производства в большинстве регионов.

В этой связи определение перспективных специализаций с точки зрения наличия в регионе перечисленных условий представляется необоснованным. При этом в Концепции не нашлось места современным подходам к оценке перспективной специализации регионов, в частности, формированию новых специализаций, «умной специализации» и т.д.

Другая серьезная проблема - в том, что даже если перспективная специализация будет корректно определена, она характеризует лишь условия для размещения тех или иных производств, но их возникновение совершенно не обязательно, особенно, если ряд конкурирующих регионов имеют примерно одинаковый набор факторов.

Множество вопросов вызывают представленные в концепции типы регионов. Типология субъектов Федерации как одна из задач разработки СПР была представлена в упоминавшемся Постановлении № 870 о содержании СПР, где поставлены две разные задачи: определение состава макрорегионов на территории страны и отнесение городов и регионов к разным типам, что, по сути, намечает два возможных пути выбора объектов для государственного регулирования пространственного развития.

Проблема формирования макрорегионов в Концепции не затрагивается, основное внимание уделено типологии регионов. В зависимости от специализации они подразделяются на регионы с выраженной сырьевой ориентацией, традиционные аграрно-индустриальные, исторически сложившиеся индустриальные, при этом в типологии не нашлось места столичным постиндустриальным регионам.

Любая типологизация регионов проводится для определенных целей и с использованием различных инструментов, включая сложные экономико-математические [Российские.., 2011], однако даже в таких случаях не удается избежать упрощений и потери важных качеств классифицируемых объектов. В Концепции для типологизации сложных социально-экономических систем, каковыми являются регионы, предлагается использовать один критерий - специализацию их хозяйства, представленную в весьма примитивном виде. Если такой подход будет реализован, за каждым регионом на перспективу будет закреплен его «статус», в соответствии с которым федеральные власти будут проводить экономическую политику. Не только необоснованность, но и вред такого подхода очевидны, например, регион, получивший «статус» аграрно-индустриального, обречен остаться таковым надолго.

При обосновании направлений и изменения структуры региональных экономик и системы расселения в Концепции использованы некоторые сентенции, которые представляют широко распространенные мнения, не получившие достаточных научных обоснований, например, рекомендации о диверсификации экономики, которые даны для сырьевых и аграрно-индустриальных регионов. Однако «диверсификация ради диверсификации» не будет эффективной стратегией для экономики любого региона [Михеева, 2016]. Во-первых, проблема определения направлений эффективной диверсификации по сути своей не может быть решена в рамках отдельного региона, поскольку связана с выходом региональной продукции и услуг на новые рынки либо расширением присутствия на существующих, и рассматриваться она должна в рамках межрегиональных взаимодействий, позволяющих оценить направления взаимовыгодной специализации регионов.

Во-вторых, диверсификация сама по себе как процесс более равномерного распределения экономического потенциала между возможными направлениями его использования вряд ли может выступать как самостоятельная стратегия развития региона. В отличие от других стратегий, к примеру, повышения конкурентоспособности региона, предполагающей выбор приоритетов 
долгосрочного развития и их последующую поддержку, диверсификация может рассматриваться как дополнение к стратегиям роста, основу которых составляет специализация.

Другая сентенция такого рода - о том, что экономический рост сосредоточен в крупных городах и городских агломерациях, также не находит убедительного научного обоснования. Дальнейшее усиление процесса урбанизации, развитие крупных городских агломераций закреплены в качестве одного из приоритетов в Основах региональной политики. Однако непредвзятый анализ зарубежных литературных источников и экономики городов [Мельникова, 2017] показывает, что существуют совершенно разные модели городских систем в странах, близких по уровню жизни. Тезисы о превосходстве крупных городов с точки зрения эффективности производства и темпов экономического роста проверены на обширном статистическом материале и не нашли однозначного подтверждения. Развитие процесса урбанизации будет способствовать росту национальной экономики только в случае, если оно не сведется к концентрации ресурсов и населения в агломерациях, а обеспечит раскрытие потенциала каждого города независимо от его размера.

Анализ динамики крупнейших городов [Кузнецова, 2017] показывает, что концентрация населения в городах-миллионниках продолжает расти, однако ситуация с изменением их роли в обрабатывающих производствах и розничной торговле регионов складывается по-разному. Численность занятых в обрабатывающих производствах и доля обработки в общей занятости почти повсеместно снижаются, возможно, вследствие трансформации и модернизации самой промышленности и возрастания доли технологически сложных производств. Однако в перспективе роль крупных городов как промышленных центров будет усиливаться только в том случае, если в стране будет развиваться высокотехнологичная промышленность. Кроме того, в городах-миллионниках существует сложная проблема развития социальной сферы.

Пространственный ресурс повышения экономической эффективности в России связан скорее не с ростом уровня урбанизации, a с изменениями во внутренней структуре городской системы, с ее разнообразием [Коломак, 2017], т.е. положительное влияние на уровень общей региональной продуктивности оказывает развитие городов разных размеров.

\section{Чего не следует ожидать от Стратегии}

Утвержденная Концепция СПР разработана на период до 2025 г., что соответствует формальным требованиям закона о стратегическом планировании, в котором период более шести лет назван долгосрочным. Для чрезвычайно инерционных систем, к которым относятся региональные социально-экономические, ожидать сколько-нибудь существенных изменений в пространственном развитии страны за такой период не приходится. Более того, количественные оценки сценариев пространственного развития показывают, что межрегиональное перераспределение ресурсов, обеспечивающее реализацию сценариев, не оказывает значительного влияния на общенациональную динамику.

Альтернативные сценарии пространственного развития, сформированные при подготовке проекта Концепции СПР, оценивались в рамках содержательных гипотез двух макроэкономических сценариев развития России на период до 2030 г., разработанных в ИНП РАН [Структурно-инвестиционная.., 2017]. В консервативном сценарии проекта концепции СПР пространственная структура инвестиций в прогнозном периоде предполагалась близкой к структуре накопленных за 2000-2014 гг. инвестиций в основной капитал [Михеева, 2017]. Приоритетами инвестирования являлись столичные агломерации, нефтегазодобывающие и стратегически приоритетные регионы. В сценарии конкурентного роста приоритетами инвестирования предполагались крупные агломерации и современные регионы-лидеры. В сценарии диверсифицированного роста пространственный рост основывался на внутренних (эндогенных) источниках и эффективном использовании потенциала межрегиональных взаимодействий.

При базовом варианте макроэкономического прогноза, предполагавшем среднегодовые темпы роста национальной экономики на уровне $1-2 \%$, за счет пространственного перераспределения инвестиций в конкурентном сценарии при прочих равных условиях к концу периода может быть получено дополнительно 2,7 п.П. роста ВРП по сравнению с консервативным, за счет диверсифицированного - 1 п.п. Более существенны различия по потреблению домашних хозяйств, динамике розничной торговли, по промышленности различий практически нет. В высоком варианте макропрогноза среднегодовые темпы роста национальной экономики предполагались на уровне 3-4\%. 
В этом случае при прочих равных условиях к концу периода за счет изменения пространственных пропорций инвестиций может быть получено 1,5 п.п. в диверсифицированном сценарии, в сценарии конкурентного роста - 3,8 п.П. прироста суммарного ВРП, т.е. разница годовых темпов составляет около 0,1-0,2 п.п.

Таким образом, разница суммарного вклада в экономический рост от реализации разных пространственных сценариев невелика, т.е. предполагаемые в сценариях изменения пропорций распределения инвестиций при принятых гипотезах относительно роста национальной экономики не оказывают существенного влияния на ее динамику. Представленные оценки параметров прогнозных сценариев не учитывают рисков и негативных социальных и экономических последствий, возникающих при реализации сценариев, таких как усиление межрегиональной дифференциации, возможное ухудшение экономической ситуации на ряде территорий, увеличение объемов ресурсов, необходимых для сглаживания межрегиональных диспропорций и поддержания депрессивных регионов. Эти риски наиболее высоки в сценарии конкурентного роста.

Долгосрочный макроэкономический прогноз ИНП РАН с предполагаемыми темпами роста ВВП на уровне 3-4\% можно отнести к оптимистическим, рост российской экономики, заложенный в долгосрочном прогнозе Минэкономразвития, еще скромнее. Ожидать, что на решение проблем пространственного развития могут быть направлены значительные ресурсы, не приходится. В реализации СПР, если она, как и Концепция, будет принята на период до 2025 г., переломить инерцию пространственного развития вряд ли удастся. В этой связи в Стратегии основное внимание должно уделяться созданию экономических механизмов и институциональных условий [Зубаревич, 2015], обеспечивающих решение наиболее острых проблем в регионах, а также дающих возможности активизировать эндогенные факторы роста регионов.

\section{$* * *$}

Мы ограничились анализом официально принятых документов, относящихся к разработке Стратегии пространственного развития, который пока не дает оснований для оптимизма и уверенности в том, что Стратегию не постигнет судьба уже принятых на федеральном уровне стратегий развития федеральных округов. Вместе с тем научной общественностью высказан целый ряд предложений, содержащих конструктивные идеи разработки СПР, был подготовлен проект концепции СПР, учитывающий различные позиции экспертов, участвовавших в его обсуждении. Однако утвержденная Концепция стратегии пространственного развития показывает, что все эти предложения пока не услышаны властью.

\section{Литература}

Адамеску А.А. Первая генеральная схема: опыт объединения научных организаций для обоснования размещения производительных сил. М.: СОПС 2016. 328 c.

Жихаревич Б., Прибышин Т. Апробация подходов к изучению содержания муниципальных стратегий //Регион: экономика и социология. 2014. № 2 C. $216-234$

Журба В.В., Брязгина Е.В., Перова М.М. Анализ стратегий социальноэкономического развития субъектов Российской Федерации. Типовые ошибки и лучшие решения //Актуальные проблемы гуманитарных и естественных наук. 2016. № 4-2. C.49-52.

Зубаревич Н.В. Стратегия пространственного развития после кризиса: от больших проектов к институциональной модернизации //Журнал Новой экономической ассоциации. 2015. № 2 (26). С. 226-230.

Ильина И.Н., Плисеикий Е.Е., Копыченко Г. С., Рыбина Е.Г. Оценка качества разработки региональных стратегий развития в России// Региональная экономика: теория и практика. 2016. № 4 (427). С. 178-196.

Коломак E. A. Развитие городской системы России: ресурсы и результаты // Труды Гранберговской конференции. Новосибирск, 10-13 окт. 2016 г. Сб. докладов Междунар. конф., посвящ. 80-летию со дня рождения акад. А.Г. Гранберга «Пространственный анализ социально-экономических систем: история и современность» / Под ред. В.И. Суслова, Л.В. Мельниковой. Новосибирск: Изд-во ИЭОПП СО РАН, 2017. С. 253-264.

Конщепщия Стратегии пространственного развития Российской Федерации на период до 2030 года. Проект. Министерство экономического развития РФ. Москва, 2016 [Эл. ресурс]. URL: http://карьеры-евразии.pф/uploadedFiles/files/ Kontseptsiya SPR.pdf (дата обрашения: 15.01.2018).

Кузнецова О.В. Сдвиги в занятости и качестве жизни населения российских городов-миллионников // Проблемы прогнозирования. 2017. № 6. С. 121-131.

Мельникова Л.В. Долгосрочные стратегии регионального развития: перспективы роста и ограничения // Проблемы теории и практики управления. 2013. № 1. C. 79-88.

Мельникова Л.В. Размеры городов, эффективность и экономический рост // ЭКО. 2017. № 7. С. 5-19.

Михеева Н.Н. Диверсификация структуры регионального хозяйства как стратегия роста: за и против //Регион: экономика и социология. 2016. № 4 C. $196-217$. 
Михеева Н.Н. Оценка сценариев пространственного развития российской экономики до 2030 года // Науч. труды: ИНП РАН. М.: МАКС Пресс, 2017 C. $405-423$.

Рейтинг качества стратегий социально-экономического развития регионов России на апрель 2013 года: лидеры планирования [Эл. ресурс]. URL https://raexpert.ru/researches/regions/soc_eco_regions_04_2013 (дата обращения: 05.02.2018).

Российские регионы: экономический кризис и проблемы модернизации / Под ред. Л. М. Григорьева, Н. В. Зубаревич, Г. Р. Хасаева. М.: ТЕИС, 2011. 357 с.

Селиверстов В.E. Региональное стратегическое планирование: от методологии к практике. Новосибирск: ИЭОПП СО РАН, 2013. 436 с.

Смирнова О.О. Стратегическое государственное планирование в России. М.: Изд-во МНЭПУ, 2010. 175 с.

Структурно-инвестиционная политика в целях обеспечения экономического роста в России: монография /Под науч. ред. акад. В.В. Ивантера. М.: Научный консультант, 2017. 196 с.

Чугуевская E.C. Стратегия пространственного развития в системе документов стратегического планирования Российской Федерации [Эл. ресурс]. URL: http://2016.forumstrategov.ru/upload/program/Chuguevskaya_2.1.pdf (дата обращения: 05.02.2018).

Чугуевская E.C. О территориально-пространственных аспектах стратегии пространственного развития Российской Федерации // Архитектура и строительство. 2017. Вып.1. С. 67-71.

Capello R., Caragliu A., Fratesi U. Global Trends and the Economic Crisis: future alternative European Growth Strategies, GRINCOH Working Paper Series. 2014. Policy Paper No. 3. [Эл. pecypc]. URL: http://www.grincoh.eu/media/policy/ grincoh wp policy 3 capello caragliu fratesi.pdf (дата обращения: 10.02.2018).

Making Europe Open and Polycentric. Vision and Scenarios for the European Territory towards 2050. ESPON2013 Programme. September 2014 [Эл. pecypc] URL: http://www.et2050.eu/attachments/article/523/ESPON_Vision-Scenarios_2050. pdf (дата обращения: 10.02.2018).

Статья поступила 19. 02.2018

\section{Summary}

Mikheeva N.N., Institute of Economic Forecasting, RAS, Moscow

Strategy of Spatial Development: New Stage or Repetition of Old Mistakes?

Problems of development of the documents of strategic planning concerning spatial development at the federal level are discussed. It is shown that the strategies of long-term development of federal districts accepted by the federal government in 2010-2011 did not become the real tool of the solution of problems of spatial development.

Analysis of official documents accepted by the Government on the basis of which Strategy of spatial development is developed now is carried out. Theoretical prerequisites of the Concept of strategy, and problems which follow from their use are discussed. The central idea of the Concept is definition of perspective economic specialization of regions without interregional interaction. It is shown that the typology of regions offered in the Concept does not consider modern trends of development of regions. The offered directions of change of structure of regional economies have no convincing scientific justification.

It is shown that if in the long term low development rates of the Russian economy remains, then possibilities of purposeful impact on proportions of spatial development are small. There are considerable risks of preservation of the developed trends. It is offered to enhance attention to activization of factors of endogenous growth of regions.

Strategy of spatial development; regional factors of growth; specialization; economic growth

\section{References}

Adamesku A.A. (2016) Pervaya general'naya skhema: opyt ob"edineniya nauchnykh organizatsiy dlya obosnovaniya razmeshcheniya proizvoditel'nykh sil. Moscow, SOPS Publ. 328 p. (In Russ.)

Zhikharevich B., Pribyshin T. (2014) Aprobatsiya podkhodov k izucheniyu soderzhaniya munitsipal'nykh strategiy. Region: ekonomika i sotsiologiya. [Region: economy and sociology]. No 2. Pp. 216-234. (In Russ.)

Zhurba V.V., Bryazgina E. V., Perova M.M. (2016) Analiz strategiy sotsial'noekonomicheskogo razvitiya sub"ektov Rossiyskoy Federatsii. Tipovye oshibk i luchshie resheniya. Aktual'nye problemy gumanitarnykh $i$ estestvennykh nauk. [Current problems of humanitarian and natural sciences]. No 4-2. Pp.49-52. (In Russ.)

Zubarevich N.V. (2015) Strategiya prostranstvennogo razvitiya posle krizisa: ot bol'shikh proektov k institutsional'noy modernizatsii. Zhurnal novoy ekonomicheskoy assotsiatsii [Journal of the new economic association]. No 2 (26). Pp. 226-230. (In Russ.)

Il'ina I. N., Plisetskiy E.E., Kopychenko G.S., Rybina E. G. (2016) Otsenka kachestva razrabotki regional'nykh strategiy razvitiya $\mathrm{v}$ Rossii. Regional'naya ekonomika: teoriya i praktika. [Regional economy: theory and practice]. No 4 (427). Pp. 178-196. (In Russ.)

Kolomak E.A. (2017) Razvitie gorodskoy sistemy Rossii: resursy i rezul'taty. Trudy Granbergovskoy konferentsii. Novosibirsk, 10-13 okt. 2016 g. Sb. dokladov Mezhdunarodnoi konferencii, posvyashchennoi 80-letiyu so dnya rozhdeniya akad. A. G. Granberga 'Prostranstvennyy analiz sotsial'no-ekonomicheskikh sistem: istoriva i sovremennost' Novosibirsk, IEOPP SO RAN Publ. Pp. 253-264. (In Russ.)

Kontseptsiya Strategii prostranstvennogo razvitiya Rossiyskoy Federatsii na period do 2030 goda. Proekt. (2016) Ministerstvo ekonomicheskogo razvitiya RF. (In Russ.) Available at: http://kar'ery-evrazii.rf/uploadedFiles/files/Kontseptsiya_SPR. pdf (accessed 15.01.2018).

Kuznetsova O V. (2017) Sdvigi v zanyatosti i kachestve zhizni naseleniya rossiyskikh gorodov-millionnikov. Problemy prognozirovaniya. [Studies on russian economic development]. No 6. Pp.121-131. (In Russ.)

Melnikova L. V. (2013) Dolgosrochnye strategii regional'nogo razvitiya: perspektivy rosta i ogranicheniya. Problemy teorii i praktiki upravleniya. [Problems of the theory and practice of management]. No 1. Pp. 79-88. (In Russ.). 
Melnikova L.V. (2017) Razmery gorodov, effektivnost' i ekonomicheskiy rost. EKO [ECO]. No 7. Pp. 5-19. (In Russ.)

Mikheeva N.N. (2016) Diversifikatsiya struktury regional'nogo khozyaystva kak strategiya rosta: za i protiv. Region: ekonomika i sotsiologiya [Region: economy and sociology]. No 4. Pp. 196-217. (In Russ.)

Mikheeva N.N. (2017) Otsenka stsenariev prostranstvennogo razvitiya rossiyskoy ekonomiki do 2030 goda. In: Nauchnye Trudy: Institut narodnokhozyaistvennogo prognozirovaniyza RAN [Scientific articles - Institute of economic forecasting Russian academy of sciences]. Moscow, MAKS Press Publ. Pp. 405-423. (In Russ.)

Reyting kachestva strategiy sotsial'no-ekonomicheskogo razvitiya regionov Rossii na aprel' 2013 goda: lidery planirovaniya (2013). (In Russ.) Available at: https://raexpert.ru/researches/regions/soc_eco_regions_04_2013 (accessed 15.01.2018).

Rossiyskie regiony: ekonomicheskiy krizis i problemy modernizatsii (2011). Moscow, TEIS Publ. 357 p. (In Russ.)

Seliverstov V.E. (2013) Regional'noe strategicheskoe planirovanie: ot metodologii k praktike. Novosibirsk, IEOPP SO RAN Publ. 436 p. (In Russ.)

Smirnova O.O. (2010) Strategicheskoe gosudarstvennoe planirovanie v Rossii. Moscow, MNEPU Publ. 175 p. (In Russ.)

Strukturno-investitsionnaya politika v tselyakh obespecheniya ekonomicheskogo rosta v Rossii (2017) Moscow, Nauchnyy konsul'tant Publ. 196 p. (In Russ.)

Chuguevskaya E.S. (2016) Strategiya prostranstvennogo razvitiya v sisteme dokumentov strategicheskogo planirovaniya Rossiyskoy Federatsii. (In Russ.) Available at: http://2016.forumstrategov.ru/upload/program/Chuguevskaya_2.1.pdf. (accessed 15.01.2018).

Chuguevskaya E.S. (2017) O territorial'no-prostranstvennykh aspektakh strategii prostranstvennogo razvitiya Rossiyskoy Federatsii. Arkhitektura i stroitel'stvo. [Architecture and construction], Vyp.1. Pp. 67-71. (In Russ.)

Capello R., Caragliu A., Fratesi U. (2014) Global Trends and the Economic Crisis: future alternative European Growth Strategies. GRINCOH Working Paper Series. Policy Paper No. 3. Available at: http://www.grincoh.eu/media/policy/ grincoh_wp_policy_3_capello_caragliu_fratesi.pdf (accessed 10.02.2018).

Making Europe Open and Polycentric. Vision and Scenarios for the European Territory towards 2050. (2014). ESPON2013 Programme. September 2014. Available at: http://www.et2050.eu/attachments/article/523/ESPON_Vision-Scenarios_2050. pdf. (accessed 10.02.2018). 